\title{
CHRONIC NEUTROPENIA
}

\author{
BY \\ MURIEL M. MCLEAN \\ From the Royal Aberdeen Hospital for Sick Children
}

(RECEIVED FOR PUBLICATION JUNE 14, 1957)

Kostmann (1956) has drawn attention to the existence of a state of chronic neutropenia which may account for recurrent infections in certain children. This state of neutropenia is distinct from that occurring in leukaemia, in toxic states, in infectious diseases, or as a feature of cyclic neutropenia. Kostmann studied six children of whom three died of overwhelming infection before the age of 6 months, and one at the age of 3 years. The remaining two, who were less severely affected, were both alive four years later, but in one the granulocytes in the blood had increased, and in the other there had been no blood counts from the age of 5 months. A study of the families of these children showed that eight other children had died in infancy with a history suggesting agranulocytosis. In one family in which there had been much inbreeding, one branch showed one affected child who had been fully investigated and three elder children who had presented a similar picture; three other branches each showed an affected child who had been fully investigated, and in each of three further branches of the same family a child had died with the same clinical picture. In two other families the parents were closely related. These findings led Kostmann to suggest that the disease was due to a recessive gene and to label these cases 'infantile genetic agranulocytosis'.

There are no other reports of this disease occurring in more than one member of a family. Fanconi (1941) described two infants aged 7 months in whom the granulocytopenia was associated with mild recurrent infections over a period of several months, but in whom recovery eventually took place. Hotz (1941) described agranulocytosis in a girl of 4 months who had suffered from furuncles at the age of 2 weeks. Her blood count was normal two and a half years later. Tobler and Buser-Plüss (1942) described agranulocytosis in a girl of 10 months who had a history of infections from the age of 3 weeks. She was under observation for six months, but her further progress is not recorded.
Salomonsen (1948) described another single case, a child of 9 months, in whom granulocytopenia persisted for one and a half years, gradually decreasing after one year. Ström (1949) described a child of 15 months with granulocytopenia for 10 months, but in this case the picture was somewhat different in that the patient had recurrent exanthemata.

The case reported here is another example of the condition and is of interest as the granulocytopenia still persists at the age of 4 years 3 months.

\section{Case Report}

Caroline was admitted to the medical ward of the Royal Aberdeen Hospital for Sick Children on November 10, 1954. She was then 23 months old, the second child of healthy parents. Apart from respiratory infection her brother, aged 4 years, had been healthy. She had always been prone to skin sepsis. At the age of 3 days she developed septic spots on the scalp; at the age of 1 month an axillary abscess was incised and she had a paronychia at the same time. She was treated with penicillin and chloramphenicol. At 3 months a preauricular abscess was incised and treatment was with chloramphenicol; at 13 months she suffered from multiple abscesses including a parotid abscess and a submandibular abscess which was incised. Treatment on that occasion was chlortetracycline, sulphadiazine and penicillin. A blood count then showed total white cells 9,500 (neutrophil polymorphs $5 \%$, eosinophils $30 \%$, lymphocytes $55 \%$, monocytes $8 \%$, Türk cells $1 \%$, atypical lymphocytes $1 \%$ ) but the significance of the low neutrophil count was overlooked. At 18 months of age she developed a staphylococcal infection of the skin which persisted for three months; at 20 months she developed otitis media which was treated with penicillin, and for four months before admission she had had a persistent cough which had become worse two days before admission.

On admission she was not acutely ill but her breathing was distressed. Examination of the chest suggested a right upper lobe pneumonia and a radiograph showed that the right upper and mid zones were opaque and that there were scattered opacities throughout both lungs suggesting bilateral bronchopneumonia. Treatment with sulphadiazine in doses of $0.5 \mathrm{~g}$. six-hourly was started but discontinued after three doses when the blood 
count showed 7,400 white cells (neutrophil polymorphs $0 \%$, eosinophils $2 \%$, basophils $1 \%$, lymphocytes $50 \%$, monocytes $44 \%$, Türk cells $3 \%$ ). As the child remained afebrile, no further treatment was given then.

\section{Investigations}

Investigations. The Mantoux test ( 1 in 1,000 old tuberculin) was negative. No tubercle bacilli were cultured from fasting gastric juice inoculated in guineapigs.

A normal amount of gamma globulin in the blood was shown by electrophoresis on two occasions (November 19, 1954, and May 14, 1955).

Bone Marrow (November 23, 1954). Premyelocytes $11 \cdot 5 \%$, n. myelocytes $3 \cdot 5 \%$, e. myelocytes $2 \%$, m. metamyelocytes $11 \%$, e. metamyelocytes $6.5 \%$, n. polymorphs $0.5 \%$, e. polymorphs $0.5 \%$, lymphocytes $30 \cdot 5 \%$, monocytes $20 \%$, plasma cells $7 \cdot 5 \%$, early normoblasts $2 \%$, intermediate normoblasts $0.5 \%$, late normoblasts $2 \cdot 5 \%$, megakaryocytes present and producing platelets.

Bone Marrow (December 3, 1954). Myeloblasts 0 $3 \%$, premyelocytes $7 \cdot 0 \%$, n. myelocytes $2 \cdot 7 \%$, e. myelocytes $3 \cdot 0 \%$, n. metamyelocytes $2 \cdot 7 \%$, e. metamyelocytes $7 \cdot 7 \%$, n. polymorphs $0.3 \%$, e. polymorphs $2 \cdot 0 \%$, lymphocytes $43 \cdot 7 \%$, monocytes $12 \cdot 3 \%$, plasma cells $2 \cdot 3 \%$, proerythroblasts $1 \cdot 3 \%$, early normoblasts $2.7 \%$, intermediate normoblasts $2.0 \%$, late normoblasts $8 \cdot 7 \%$.

BLood Counts. White blood counts in the patient's family were as follows:

Mother. White blood count 7,400 (n. polymorphs $82 \%$, lymphocytes $15 \%$, monocytes $3 \%$ ).

Father. White blood count 10,500 (n. polymorphs $56 \%$, eosinophils $5 \%$, basophils $2 \%$, lymphocytes $26 \%$, monocytes $11 \%$.)

Brother. White blood count 3,500 (n. polymorphs $56 \%$, eosinophils $6 \%$, lymphocytes $33 \%$, monocytes $5 \%$ ).

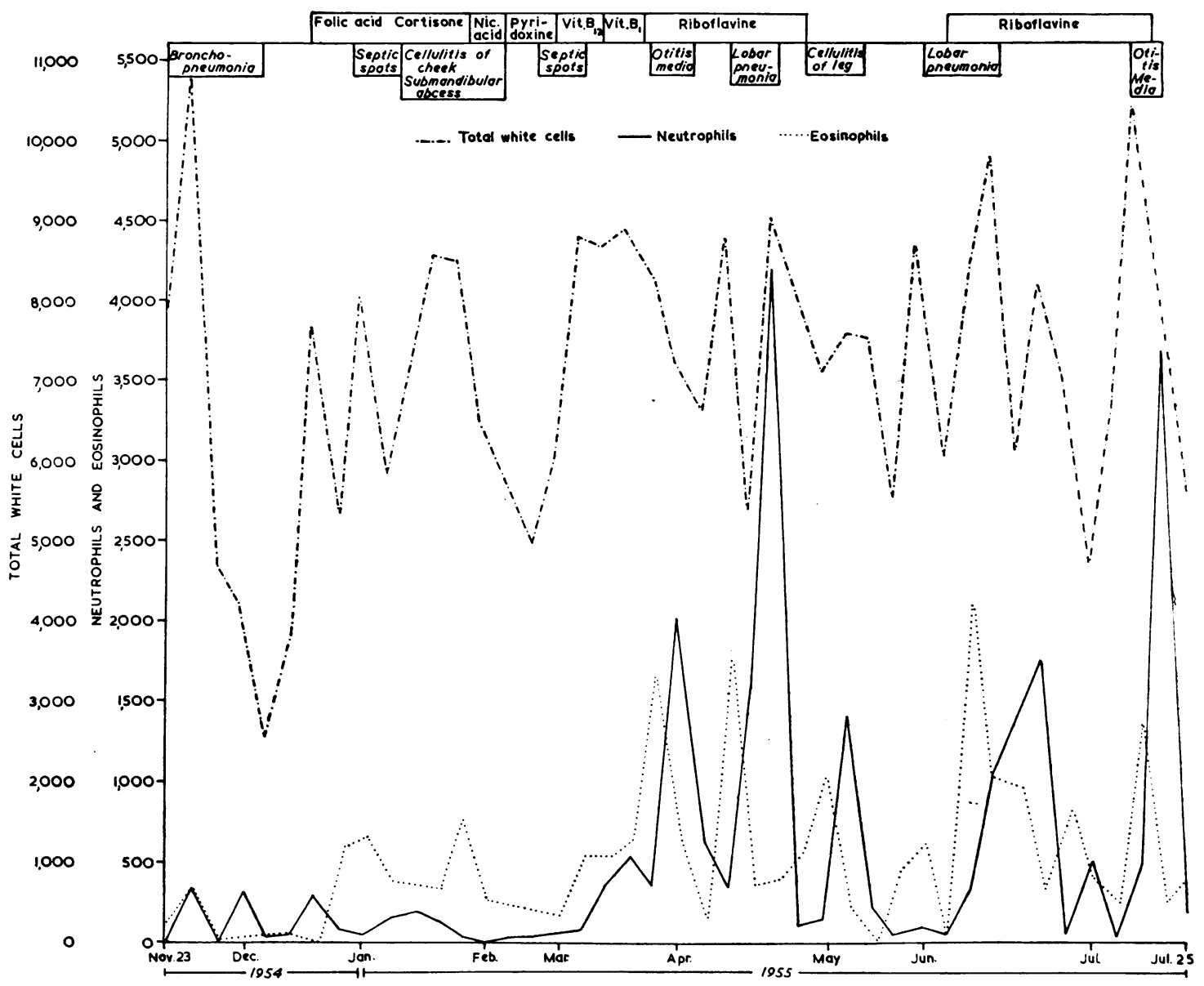

FIG. 1. 
Throughout Caroline's stay in hospital 93 blood counts were done at frequent intervals. The accompanying chart shows a selection of those counts and their relation to treatment and to infections.

Infections included bronchopneumonia, two attacks of lobar pneumonia in which the upper lobe of the right lung was the affected area, two attacks of otitis media, cellulitis of a leg, cellulitis of the face accompanied by a submandibular abscess, and recurrent septic spots.

The various substances given in an attempt to raise the neutrophil count were folic acid, $10 \mathrm{mg}$. three times a day for 17 days; cortisone $75 \mathrm{mg}$. per day for three days followed by $50 \mathrm{mg}$. per day for 10 days and withdrawn over a further four days; nicotinic acid $120 \mathrm{mg}$. daily for 10 days; pyridoxine $100 \mathrm{mg}$. daily for 10 days, followed by $200 \mathrm{mg}$. daily for six days; four doses of 1,000 micrograms vitamin $B_{12}$ over a period of 12 days; $100 \mathrm{mg}$. vitamin $B_{1}$ daily for 10 days; riboflavine $30 \mathrm{mg}$. daily for one period of 36 days; and for another period of 46 days. None of these substances produced and maintained a rise in neutrophils.

Caroline was discharged from hospital on July 25 , 1955, and has been seen on nine occasions since then, the last time in March, 1957. The white cell counts have varied from 2,200 to 7,600: neutrophil polymorphs were absent when she was last seen, and on two other occasions, while on the other six occasions the neutrophil counts varied from 100 to 1,300 .

\section{Discussion}

When this child was first seen, the possibility of granulocytopenia being due to the toxic effect of sulphadiazine was considered, particularly as the blood count previously recorded also followed treatment with sulphadiazine. Her history of recurrent infections and her subsequent progress, however, suggest that the granulocytopenia was not caused by sulphadiazine and had existed from birth.

Kostmann's suggestion that this condition might be familial led to investigation of the whole family. The parents were not related and there was no history of relatives either dying in early infancy or suffering from recurrent infections. Blood counts on her father, mother and brother failed to show any neutropenia.

Despite the low neutrophil count the total white blood cells rarely fell to very low levels although readings as low as 2,200 were recorded. This agrees with the findings in most of the reported cases. Bone marrow examination showed maturation arrest of the granulocyte series. Kostmann found this in some of his cases, and as cell culture experiments with bone marrow had shown that activation and maturation of cells were obtained when cysteine or normal serum was added, he gave cysteine orally, subcutaneously and intravenously to one child but without any effect. Caroline had been discharged from hospital before this work became known. As she lived 35 miles away regular blood counts were impossible, and it was considered that re-admission to hospital with its risks of infection in order to try the effect of cysteine was not justifiable. While she was in hospital folic acid, cortisone, pyridoxine, vitamin $B_{12}$, vitamin $B_{1}$ and riboflavine were all administered in turn without effect. At first it seemed that riboflavine might be producing a rise in neutrophil polymorphs, as counts of 4,200 , $3,600,2,100$ and 2,000 were recorded while she was on that treatment, but the count fell on one occasion to 80 , and on another to nil while she was still on riboflavine. On every occasion the rise in neutrophils was preceded by an infection, on two occasions otitis media and on two occasions pneumonia, but infections occurred at other times without any subsequent rise in neutrophils. The highest neutrophil counts were always preceded by a rise in eosinophils, a feature that has not been noted in any of the cases reported in the literature.

The problem of management of this child was great and it was decided that she should have constant treatment with antibiotics. On discharge from hospital she was having a daily dosage of $300 \mathrm{mg}$. chlortetracycline which was later changed to the same dosage of tetracycline hydrochloride. Minor skin sepsis has occurred from time to time: she has had mild respiratory infections, and radiographs of the chest still show some opacity in the upper zone of the right lung, but she has had no severe illness.

The cases reported in the literature were either not followed up to this age or the blood count had returned to normal, but in this child there is no indication of improvement.

\section{Summary}

A case of chronic neutropenia associated with recurrent infections from birth is reported in a girl now 4 years 3 months old.

Folic acid, cortisone, pyridoxine, vitamin $\mathbf{B}_{12}$, vitamin $B_{1}$ and riboflavine were all given without producing a permanent rise in neutrophil polymorphs.

On constant treatment with antibiotics the child has remained free from severe infections for almost two years.

I should like to thank Professor John Craig and Dr. Norman S. Clark for their encouragement and help in presenting this case, and the Haematology Department Aberdeen Medical School, for their numerous blood counts.

Fanconi, G. (1941). Ann. paediat. (Basel), 157, 317.

Fatz, A. (1941). Z. Kinderheilk., 62, 529.

Kostmann, R. (1956). Acta paediat. (Uppsala), 45, Suppl. 105. Salomonsen, L. (1948). Ibid., 35, 189.

Ström, J. (1949). Ibid., 38, 590.

Tobler, W. and Buser-Plüss, E. (1942). Ann. paediat. (Basel), 159 258. 